\section{REFERENCES}

1 Wigglesworth, V.B. (1934). The physiology of ecdysis in Rhodnius prolixus (Hemiptera). II. Factors controlling moulting and 'metamorphosis'. Quart. $J$. Micr. Sci. 77, 191-222.

2 KOPEC̈, S, (1917). Experiments on metamorphosis of insects. Bull. int. Acad. Cracovie (B), pp. 57-60.

3 KOPEC , S. (1922). Studies on the necessity of the brain for the inception of insect metamorphosis. Biol. Bull., Woods Hole 42, 322-42.

4 WigGlesworTh, V. B. (1940). The determination of characters at metamorphosis in Rhodnius prolixus (Hemiptera). J. Exp. Biol. 17, 201-222.

5 WigGlesworth, V. B. (1936). The function of the corpus allatum in the growth and reproduction of Rhodnius prolixus (Hemiptera), Quart. J. Micr. Sci. 79 91-121
6 FUKUDA, S. (1940). Induction of pupation in silkworm by transplanting the prothoracic gland. Poc. Imp. Acad. Japan 16, 414-16.

7 WigGlesworTH, V. B. (1940). Local and general factors in the development of 'pattern' in Rhodnius prolixus (Hemiptera). J. Exp. Biol. 17, 180-200.

8 Wigglesworth, V.B. (1954). The Physiology of Insect Metamorphosis. Cambridge University Press, $152 \mathrm{pp}$.

9 avery, O. T., Macleod, C. M. \& McCarty, M (1944). Studies on the chemical nature of the substance inducing transformation of pneumococcal types. $J$. Exp. Med. 79, 137-58.

10 Wigglesworth, V. B. (1953). The origin of sensory neurones in an insect, Rhodnius prolixus (Hemiptera). Quart. J. Micr. Sci. 94, 93-112.

11 WOLPERT, L. (1969). Positional information and the spatial pattern of cellular differentiation. $J$. Theor. Biol. $25,1-47$.

12 Nishout, H. F. (1978). Wing pattern formation in Lepidoptera: a model. J. Exp. Zool. 206, $119-136$.

13 Numout, H. F. (1985). The developmental physiology of color patterns in Lepidoptera. Adv. Insect Physiol. $18,181-247$.

Sir V. B. WIGGLESWORTH is at the Department of Zoology, University of Cambridge, Downing St. Cambridge CB2 $3 E J, U K$.

\title{
SCIENCE AND SOCIETY
}

\section{Visit to China: Part 2}

\author{
Wendell W. Weber
}

In the June issue of BioEssays (Vol 8, No. 6, pp. 210), the first part of a report by Wendell $W$. Weber on a visit by American geneticists to the People's Republic of China, under the auspices of the Citizen Ambassadors Program of the People to People organization, was published. The second and concluding part of the report follows below.

Kunming- 2 November 1987: The Family Planning Institute, Kunming Medical College, the Institute of Medical Biology, Academy of Medical Sciences, the Institute of Zoology, Academia Sinica. In Kunming the delegates divided into two groups, the first of which visited the Family Planning Institute, Kunming Medical College, and the Institute of Medical Biology, Academy of Medical Sciences, while the second group visited the Institute of Zoology and its primate colonies, Academia Sinica. For the first group, the day's agenda began with their visit to the Family Planning Institute. They were welcomed by Dr Luo Yu, the Director, who told us the Institute had been founded in 1981 to conduct clinical and basic research into male sterility and other health problems of the ethnic minorities of Yunnan Province. The study of the genetic causes of these disorders receives high priority at the Institute. Clinical research involves ob- stetrics, gynecology and radioimmunology, whereas basic research is directed chiefly toward the use of Chinese herbal medicines for remedial treatment of male sterility and the development of improved contraceptive methods. The research staff of the Institute, which numbers 22 scientists, and the Institute itself have received local and national recognition for research achievements. Demographic, economic and geographic data collected on 16 of the 24 ethnic minorities of Yunnan Province were summarized for us. Minorities are customarily examined and treated at temporary clinics set up where they live. Physical and dental exams, routine blood tests, dermatoglyphic studies, and so on are conducted and aspects of family planning are introduced. The delegates toured the Radioimmunology Laboratory where the ways of immobilizing sperm and detection of surface antigens of sperm are under study, and where RIA measurements are performed and use of steroid hormones for diagnosis and treatment of disorders of contraception and post-menopausal states are investigated. We also visited the Human Cytogenetics Laboratory where demonstrations of banding of chromosomes from chorionic samples, karyotypes of chromosomal anomalies, dermatoglyphic patterns and photo albums of aberrations and gross anomalies are displayed.
At Kunming Medical College, opening remarks were made by Dr Chen De Chang, President of the College and by $\mathrm{Dr} \mathrm{Bi}$ Mo, Head of the Foreign Relations Committee. The College was established in 1937 as part of one of the regional Universities of China, Nin Mang University, and is now one of 44 medical colleges in China. Classes of 145 students have been trained as doctors there each year since 1979. As in Beijing, the academic program takes eight years to complete and leads to the Master of Science degree. The program consists of six years to the Bachelor of Medicine and two years more of internship. Academic research has been conducted at the College since 1981-2. Dr Jing An-Lu and her colleagues gave an extensive report on the uses of dermatoglyphics in their study of variation in the Han and minority populations, and Professor Shi reported on the abnormal hemoglobins and G6PD variants in these populations. Delegates toured the campus and were shown the permanent collection of anatomic anomalies which is located in the large new laboratory building by Professor Wan, Director of Pathology. In addition to their medical education, all medical students donate two weeks of full-time labor each year to campus beautification.

For the afternoon session, the first group of delegates was bussed high into 


\section{SCIENCE AND SOCIETY}

the hills outside of Kunming to the Institute of Medical Biology. After a brief introduction by its Deputy Director, Mr Dong De-Xiang, delegates were ushered to the lecture hall where over 200 researchers and students attended lectures by Drs Chu, Fisher, Vinogradov and Borowsky. Unlike Beijing and Shanghai, where scientists and students use English extensively, in Kunming Dr Chu gave his lecture in Chinese and the lectures of the other speakers were translated sentence-bysentence into Chinese by local scientists who had advance copies of the talks. Despite some errors in translation, the lectures went smoothly and attracted a great deal of interest and an enthusiastic response from the audience.

Meanwhile during the morning, the second group had been bussed to the Institute of Zoology and the primate colonies situated adjacent to the Institute of Medical Biology. The Deputy Director of the Institute of Zoology, Dr Xiong Jiang, standing in for the Director, Dr Shi Liming, who was away in Washington, D.C., gave us a brief introduction to the Institute. It had been established in 1958 to conserve, develop and carry out research on the animal resources in the subtropical and tropical regions of Yunnan and southwest China. To achieve those ends, the Institute has initiated several internal research programs and on numerous occasions its scientists have collaborated with investigators from several foreign countries. Another part of its mission is to train new scientists, and since 198165 Master's Degrees have been awarded by the Institute. The first Ph.D. was awarded this year. Although the thrust of this Institute is seemingly somewhat removed from the direct interests of the delegation, a clear focus on cytogenetics and population genetics of Yunnan fauna was evident from informal discussions with the scientists of the Institute, from the repository of more than 70 cell lines of animals of southwest China that is maintained, and from many excellent photos of their work we saw on a tour of the laboratories. Subject matter varied from microchromosomes of birds through population genetics of Muntjacs (a deer-like animal) and Oryzias (a fish that thrives in the rice paddies) to electron photomicrographs of the spermiogenesis of Drosophila melanogaster. A major effort is directed toward the search for a monoclonal antibody against human sperm surface antigens that would be active in either the male or female genital tract, with population control the obvious motive. Another laboratory is engaged in developing antivenoms as drugs to be used in humans against poisonous snakes of the region. Although the facilities and technology of the Institute are primitive by US standards, the delegation was favorably impressed by the basic biologic studies in progress at the Institute. We were also impressed by the natural history museum with more than 1000 excellent specimens of Yunnan fauna. A high point of the museum visit was a newly stuffed tiger that had killed three people on the outskirts of Kunming last spring. It had not yet been removed from the taxidermy laboratory. The primate colony contains more than 400 animals and the broad scope of primatological investigations covers breeding, behavior, ecology, anatomy, neurophysiology and immunology. Though our visit to the primate colony was short, it was enough for us to see that the animals are well cared for and that the Institute will probably succeed in its goal of preserving endangered species such as the black snub-nosed monkey, of which only 400 survive in Yunnan province.

Our visit to Kunming also included a trip of some 75 miles southward from the city on roads toward Vietnam to the Stone Forest, an area of beautifully curious geologic rock formations. After lunch we were entertained at the restaurant hotel by a group of local musicians and dancers. Our progress on the bus trip, which took almost 4 hours each way, was slowed by road construction and heavy traffic, much of which was military. We departed from Kunming on an early morning flight and arrived in Shanghai before noon.

Shanghai-4 November, 1987: The Institute for Genetics, Fudan University, the Shanghai Children's Hospital, and the Shanghai branch, Chinese Medical Association. Our scientific agenda for this day included visits to the Institute for Genetics of Fudan University by approximately half of the delegation and to the clinical departments of the Shanghai Children's Hospital by the other half of the delegation. The first group went by bus to the Fudan University campus and was met by Dr Jerry Hsueh, one of three Deputy Directors of the Institute, and then escorted to a University reception room. After introductions, Dr C.C. Tan, Director of the Institute, spoke to us for about an hour. He told us that Fudan University was established in 1905 by a group who had left the
French sponsored University in Shanghai over differences in policies and other matters. Fudan University had grown gradually at first, but after 1949 at an increasing pace. About two years ago, Fudan University was chosen by the Chinese republic as one of five universities designated to receive special attention, with increases in funding and additional money for scientific equipment. Over the years, the educational system at Fudan has shifted from the Russian style of teaching to a more Western style. Growing emphasis is placed on high-technology programs, such as computer science, and on renewal of the programs in the social sciences, law and economics. Dr Tan believes that students applying for University admission are better prepared in mathematics, chemistry and the other basic sciences than were previous applicants, and that the faculty has a difficult time keeping ahead of their bright and ambitious students. $\mathrm{He}$ jokingly remarked that nowadays "they have a very high level of students, and a lower level of faculty'.

Dr Tan is a student of Thomas Hunt Morgan and Th. Dobzhansky, and he has had an illustrious career. He is now Provost of the University and Dean of the College of Life Sciences. He remains very active, in spite of his age of nearly 79 years. Among his goals for the University are: to strengthen the quality of the teaching faculty, to expand the knowledge of English (rather than Russian) by both faculty and students, to avoid premature field specialization by students (a defect of Russian education), to provide a broader base of general education for science students, and to acquire modern scientific equipment and keep it in operation. Dr Tan mentioned the same serious difficulties that Dr Luo encountered in Beijing regarding the expense of airmail delivery of scientific news, in getting prompt delivery of scientific journals, specialized chemicals, and supplies needed for such projects as those in molecular biology. Dr Tan said improvements are underway, or expected, in the efficiency of management of Chinese institutions that should make it easier to achieve some of these goals.

The Institute for Genetics at Fudan University was established in 1958. As he told us about the scientific and political climate in which the Institute had developed, Dr Tan explained that misconceptions about Lysenkoism that had retarded the development of modern genetics in Russia for so many years had had much less influence in 
China. Chairman Mao had listened to scientists like Dr Tan and supported them in rejecting the Lysenkoist claims of Russian geneticists. During those early years, the scientific objectives of the Institute stressed applied and practical research rather than basic and theoretical investigations. Students were taught how to do chromosomal analyses, to detect inborn errors of metabolism, and to determine the damaging effects of low-level radiation. At the same time, there was a laboratory of microbiology that conducted studies to find and isolate new antibiotics from microbes.

After weathering the Cultural Revolution, the Genetics Institute gained new momentum. Many of the current faculty have studied in the USA or other centres of genetics research in the Western countries, and programs to study abroad continue. Seventy to eighty new students and trainees per year study at the Genetics Institute and the staff intends to make it a showcase for genetic research and training in China. Some major areas of research that $\mathrm{Dr}$ Tan outlined for the future are, in Medical (Human) Genetics: human gene mapping, polymorphisms of mitochondrial DNA, possibilities of gene therapy; in Microbial Genetics: replication mechanisms of plasmids, structural characteristics of high-temperature-tolerant bacterial proteins; and in Plant Genetics: rice genetics and the genetic analysis of the male sterility system; mapping of chloroplast genes, artificial culture of rice cells, and the growth problems of peas, beans and other legumes.

Dr Tan said that a number of foreign institutions such as the Rockefeller Foundation, the National Science Foundation and the Thomas Morgan Foundation have supported the programs of the Genetics Institute. $\mathrm{He}$ is expecting additional support from outside China to complete the new Research Building for the Institute, which has been started, in time for an International Symposium on New Frontiers of Genetics, Drosophila Genetics, and the Impact of Genetics on Future Developments in China to be held about two years from now, at the time of his 80th birthday. The new building will house the Genetics Institute and the General Biology Department, and there will be about 200 workers in the building.

A new program at the Genetics Institute, now in its second year, is a competitive fellowship for scientists outside the Institute. There are 9 or 10 of these awarded each year to allow outside scientists to come to the Institute and conduct a research project in one of the laboratories. Salary stipends and stipends for research supplies are provided. This program appears to be working well and is bringing some additional bright people to the Institute.

We then divided into smaller groups to tour the laboratories. The Institute has seven sections: Basic Genetics, Human and Medical Genetics, Microbial Basic Genetics, Plant Molecular and Cell Genetics, Insect Evolutionary and Behavioural Genetics (Dr Tan's unit), Genetic Engineering and one on Laboratory Equipment and Laboratory techniques. Because time was short, $\mathrm{Dr}$ Tan gave us an Annual Report of the Institute that contained a more complete description of research of the Institute:

Human and Medical Genetics. Dr Liu $\mathrm{Zu}$ Dong heads this section. Investigators are working on mitochondrial DNA polymorphisms of the Han, Uighur, Kazakh and Hui populations. Thirty-one mtDNA variants have been found which are suggestive of fusion of Uighur and Kazakh populations with the Han and the Hui. Other investigators are studying the in situ hybridization of chromosomes and other genetic characters they believe will be useful in forensic medicine, oncogenes related to stomach cancer (the commonest cancer in China), and P elements in Drosophila in four local strains of this insect.

Microbial Molecular Genetics. Dr Sheng Zujia heads this section. The research in this laboratory includes the search for natural plasmids of thermophilic bacterial, the determination of mechanisms of protein stability of these temperature-resistant strains, the isolation of lysogenic strains of Bacillus stearothermophilus and the selection of strains of Saccharomyces diasticus capable of using maize or sweet potatoes as a carbon source and suitable for ethanol production.

Plant Molecular and Cell Genetics. Dr Cai Yixin heads this section. The focus of research in this section is on the genetics of rice, beans and other foodproducing plants.

Insect Evolutionary and Behaviour Genetics. Dr Tan heads this section. Research in the section encompasses the analysis of courtship songs in wildtype eye color mutant strains of Drosophila melanogaster, the sexual behaviour and courtship song in variants of Drosophila takahashii, determination of the genetic distance among species of the latter group, and attempts to produce harmful mutations in Drosophila melanogaster by laser radiation.

Genetic Engineering. Dr Shi Luji heads this section. Studies in this section are directed toward the production of clones of yeast genes, the construction of plasmid vectors for Corynebacterium, and studies of phage T5's in Bacillus subtilis. Cloning of the immunogenetic gene, and sequencing of the corresponding peptide, of the virus that causes hoof and mouth disease are also in progress.

Laboratory Equipment and Laboratory Techniques. This is the newest section of the Institute, having been established in 1984. It operates and maintains complex equipment such as the DNA synthesizer, the protein sequencer, high-voltage electrophoresis equipment, electron microscopes, liquid scintillation counters, cell culture facilities and so on. This section also provides services for other investigators, such as the synthesis of requested polynucleotide sequences, to be used as probes in cloning experiments.

Compared to other research institutions that we visited in Beijing and Kunming, the Institute of Genetics at Fudan University is, by far, the best equipped and most modern.

On the morning of the same day (4 November) a second group of the delegation visited the Laboratory of Medical Genetics of the Shanghai Children's Hospital. The laboratory, headed by Drs Tseng Yitao and Huang Suchen, a husband-wife team, focuses on research of hemoglobinopathies using molecular biology techniques.

During the afternoon session, the delegation visited the Shanghai Branch of the China Medical Association, where delegation members gave talks attended by the faculty and students of the Institute of Genetics of Fudan University and also by students and faculty from other Universities and research Institutions in Shanghai. Dr Tan welcomed and introduced $\mathrm{Dr} \mathrm{Chu}$, who presented his talk on human mutations, Dr Walton Fangman presented a lecture on DNA replicons in yeast, Drs Gary Gussin and Robert Wagner lectured on the topics mentioned previously (see Beijing-Day 1).

Prior to exiting China at Shanghai, the delegation visited the Children's Palace and a performance of professional acrobats. They also took a day trip to the old walled city of Suzhou on the Grand Canal where they saw an embroidery factory at work, a silk 


\title{
CHALLENGES
}

factory and formal public gardens of the city.

\section{Acknowledgements}

I would like to express my appreciation to Dr Ernest H. Y. Chu, Dr Junius G. Adams, Dr Richard L. Borowsky, Dr
Elof A. Carlson, Dr Elizabeth M. Center, Dr W. Scott Champney, Dr Gary N. Gussin, Dr Bert N. La Du, Jr and Dr George T. Rudkin for allowing me to use their written reports of the different parts of the trip in my preparation of this comprehensive report.
WENDELL W. WEBER is at the Department of Pharmacology, Medical Science Building 1, Rm. 6322, University of Michigan, Ann Arbor, MI 98109, USA.

\section{The Pathogenesis of Maturity-onset Diabetes Mellitus: Is There a Link to Islet Amyloid Polypeptide?}

\author{
Per Westermark and Kenneth $\mathrm{H}$. Johnson
}

Challenges presents discussions of recent findings and issues of special relevance to medicine, agriculture, or industry. In the following contribution P. Westermark and $K$. H. Johnson describe a new finding of clinical significance in the onset of diabetes mellitus.

\section{Summary}

The discovery of a novel polypeptide (Islet Amyloid Polypeptide: IAPP) isolated from human and cat islet amyloid and from amyloid of a human insulinoma is reviewed. Structurally, IAPP from the human and cat resembles calcitonin gene-related peptide (CGRP). The structural similarities between the neuropeptide CGRP and IAPP support the premise that IAPP is hormonal in nature. Our immunohistochemical studies also indicate that normal islet B-cells of several mammalian species (including man and cat) give strong immunoreactivity with antiserum directed to a synthetic peptide segment of IAPP. The fact that IAPP is deposited as amyloid in the pancreatic islets of type 2 (noninsulin-dependent) diabetics strongly supports an important but yet unknown link between IAPP and the development of this disease.

\section{Background and Review}

A wide variety of relatively diverse and sometimes controversial variables have been implicated in the etiology and pathogenesis of non-insulin-dependent diabetes mellitus (NIDDM) (type 2 or maturity onset diabetes). These variables include cellular and molecular aberrations related to insulin resistance, and impaired B-cell function with defects in insulin secretion. Insulin resistance has been associated with reduction in numbers of insulin receptors (adipose tissue, muscle, and liver), formation of anti-insulin antibodies, accelerated insulin degradation, post-receptor defects, and high levels of counter-regulatory hormones. Impaired B-cell function and insulin deficiency have, for example, been related to synthesis of abnormal proinsulin or insulin with greatly impaired biologic activity (i.e. insulinopathies), deficient glycoreceptors in the B-cell membrane, a defective adenylate cyclase system, impairment of calcium flux into the Bcells, and a variety of other abnormalities of insulin biosynthesis, storage and release. Although evidence supports the fact that most cases of NIDDM in humans have both impaired B-cell function and insulin resistance, controversy exists as to which of the two categories of defects is primary.

Despite the apparent multifactorial nature of NIDDM, and regardless of whether B-cell dysfunction is primary or secondary, the most substantial and uniform morphologic aspect of this disease with respect to the pancreatic islets is the deposition of amyloid. These pathologic and proteinaceous deposits, first reported by Opie in
$1900,{ }^{1}$ are restricted to the islets and occur in more than $90 \%$ of humans with NIDDM. Amyloid deposits do occur in the islets of non-diabetic individuals as well, but to a much lesser extent. 'Amyloid' refers to a pathologic and usually extracellularly deposited protein substance which, due to its composition of regular, fine fibrils, has certain characteristic tinctorial properties. This especially includes a strong affinity for the cotton dye Congo red and green birefringence after such staining. ${ }^{2}$ It is now well established that several small proteins are capable of forming fibrils with amyloid properties both in vivo and in vitro.

Islet amyloid (IA) deposits, similar to those found in humans, also occur in spontaneously diabetic cats and monkeys. Thus, over $65 \%$ of adult diabetic cats have IA ${ }^{3}$ Although studies in both diabetic humans ${ }^{4}$ and cats have indicated that diabetes mellitus (DM) and IA are causally related and are not simply concurrent features of aging, we only recently resolved the molecular origin of IA. The pathogenetic relationship of IA to NIDDM is still under investigation.

Over the past 15 years, we have independently and collaboratively studied and clinicopathologically characterized the DM:IA complex as it occurs in humans and adult cats. We have established that the DM:IA complex which occurs spontaneously in cats has many similarities with NIDDM in humans, and thus provides a model to 